\title{
Optimal distributed generation planning considering reliability, cost of energy and power loss
}

\author{
H. Yassami ${ }^{1 \star}$, A. Moeini ${ }^{1}$, S. M. R. Rafiei ${ }^{2}$, A. Darabi ${ }^{2}$, A. Bagheri ${ }^{3}$ \\ ${ }^{1}$ Neyshabur Branch, Islamic Azad University, Neyshabur, Iran. \\ ${ }^{2}$ Garmsar Branch, Islamic Azad University, Garmsar, Iran. \\ ${ }^{3}$ Abhar Branch, Islamic Azad University, Abhar, Iran.
}

\begin{abstract}
Accepted 1 April, 2011
This paper suggests a Pareto based Multi-objective Optimization Algorithm (MOA) called Strength Pareto Evolutionary Algorithm (SPEA) for Distributed Generation (DG) planning in distribution networks. As opposed to conventional multi-objective optimization techniques that correlate different objective functions by utilizing of weighting coefficients and create one single objective function, in SPEA, each objective function is optimized separately. Since the objective functions are in conflict with each other, the SPEA produces a set of optimum solutions instead of one single optimum one. Three different objective functions are considered in this study: (1) minimization of power generation cost (2) minimization of active power loss (3) maximization of reliability level. The goal is to optimize each objective function. The site and size of DG units are assumed as design variables. The results are discussed and compared with those of traditional distribution planning and also with Partial Swarm Optimization (PSO).
\end{abstract}

Key words: Distributed generation, distribution network planning, multi-objective optimization.

\section{INTRODUCTION}

In distribution network planning, the planners usually focus on the voltage profile, power loss, and operation cost while satisfying different constraints such as safe operation and adequate service. Growing the load demand and competitive environment put emphasize both on cost and reliability of distribution networks. Cost is typically expressed as per KWh of supplied load. A way to assess the reliability is calculating the ratio of time interval in which the electric energy is available to the whole time. Traditional planning has been implemented by reconfiguration and reinforcement of network, load switching, and capacitor installation. Nowadays, a great attention has been paid to the presence of distributed generation in distribution system planning. DG is generally defined as power generation through the relatively small units (from a few KWhs up to $10 \mathrm{MW}$ ). Gas turbines, reciprocating engines, fuel cells, solar cells, wind turbines, and micro-turbines are some of the

\footnotetext{
Corresponding author. E-mail: hossein_yassami@yahoo.com.
}

practical DG technologies (Doty and Turner, 2009; Willis, 2004; Pansini, 2007). Some advantages of DG units are improving the power quality, peak shaving, eliminating the need for reserve margin, lower impact on the environment compared to the traditional fossil and nuclear sources of power, and increasing the network capacity (Gil and Joos, 2008). Stability problems, complex protection strategies, and the islanding problem are some disadvantages of DG units.

The aim of DG planning is to find the feasible types, sizes, and configurations of DGs, considering the network constraints and economic concerns. Proper optimization tools are capable of discovering the optimal allocation of DG units, reducing the marginal costs and satisfying technical constraints. Some new analytical techniques for optimal placement of DGs have been proposed by reference (Wang and Nehrir, 2004). Systematic methods may not be able to reach optimum solution, or may have a heavy computational burden while applied to large power systems with many nodes and lines. Consequently, to solve the DG allocation problem, many researchers have worked on optimization-based methods. Minimizing the 
system losses and total cost of DG, (Gandomkar et al., 2005; Lee and Park, 2009; Hamedani et al., 2009), improving the reliability indices and voltage profile (Wang and Nehrir, 2008; Zhu et al., 2006; Kim et al., 2008; Niknam et al., 2003), are some of the goals considered. Many literatures use a single objective optimization approach which may not satisfy the other principal objectives. Some papers transform the multi-objective optimization to a single objective one by assigning a weighting coefficient to each objective function. However, conventional optimization techniques have not been designed to find multi-objective solutions in mind, evolutionary algorithms are suitable techniques for this task (Fonseca and Fleming, 1995). Therefore, in the present work, SPEA, a new MOA is employed (Zitzler and Thiele, 1999). Optimization of distribution system reliability, active power loss and power generation cost are considered as objective functions while the DGs' size and location are the optimization variables. A new model is proposed to calculate the power generation cost. Reliability level is evaluated using sector customer damage function (Ali et al., 1999). The SPEA minimizes/maximizes each objective separately and finds a set of optimum solutions, each one with its own features. The choice of optimum solution is dependent on planner's interest.

This paper is organized as follow: A proposition is done for the problem formulation, the test power system and the optimization algorithm, after which the study discusses the simulation results from technical and economical points of view. Finally, the research is concluded.

\section{PROBLEM FORMULATION}

The high-level reliability of supplying power, low power loss and low cost of power generation are generally antithesis. So system managers face with a wide range of solutions (Billinton and Allan, 1996). Here, a mathematical model for calculating the cost of electricity generation, reliability and power loss is described first. The aim is to optimize each objective function separately in a test system using SPEA.

\section{Mathematical formulation}

\section{Annual cost of the DG}

Levelized cost of energy is used in this work to calculate the total annual price of DGs. Equations (1) to (4) express the mathematical model (Doty and Turner, 2009; Short et al., 1995).

$J_{1}=\sum_{i=1}^{N_{D G}} N e t_{-} \mathrm{COE}_{i} \times P_{D G i} \times D_{D G_{i}} \times 24$

In the Equation (1), the worst case of daylong work for
DG units is considered.

Levelized cost is detailed as follows:

$$
\begin{aligned}
& N e t \_C O E=\frac{(I C C+L C C+\text { Initial_MOE }) \times C R F}{\left(0.75 \times P_{D G} \times D_{D G} \times 24\right)} \\
& +\frac{O \& M \times 0.75+\text { fuel_cost } \times 24 \times D_{D G}+\text { Annual_MOE }}{\left(0.75 \times P_{D G} \times D_{D G} \times 24\right)}
\end{aligned}
$$

On the other hand, levelized cost presents the real value of the total cost of building and operating a generating plant over its economic life converted to equal annual payments. Costs are levelized in real dollars (that is, adjusted to remove the impact of inflation) (US EIA Glossary).

In Equation (2), it is assumed that the DGs work over 300 days, with $75 \%$ of their generation capacity.

All DGs use natural gas with a heat rate of 10.35 $\mathrm{KWh} / \mathrm{m}^{3}$ (Distributed generation, penetration instruction). Therefore, fuel hourly price is calculated as follow:

$$
\text { Fuel_cost }=(100 / \text { eff }) \times 0.75 \times P_{D G} / 10.35 \times \text { fuel_cost }
$$

Capital Recovery Factor (CRF) converts a preset value into a stream of equal annual payments over a specified time at a specific interest rate (Short et al., 1995):

$$
C R F=I R \times\left(1-1 /(1+I R)^{l i f e}\right)
$$

\section{Interruption cost}

Customer interruption costs are evaluated with Customer Damage Function (CDF). The whole individual CDFs of a specified sector (that is, commercial, industrial, etc.) can be united into a representative cost function for that sector, designated as a Sector Customer Damage Function (SCDF).

The SCDF, as shown in Equation (5), can be aggregated in the system to produce a Composite Customer Damage Function (CCDF). The weighting used to produce a CCDF is usually done in terms of the perunit energy for each sector. CCDF is a suitable way of modeling the reliability worth (Ali et al., 1999; Billinton and Allan., 1996).

Reliability data is extracted from (Tollefson et al., 1994). The data is updated employing inflation rate, given in US International Monetary Fund (IMF). Tables 1 and 2 show the SCDF and CCDF respectively.

$$
C C D F_{S_{i}}=\sum_{i=1}^{T_{N S}} W_{S_{i}} \times S C D F_{S_{i}}
$$

Therefore the second objective is defined as follow: 
Table 1. (SCDF) (\$/kW) (1992).

\begin{tabular}{lccc}
\hline \multirow{2}{*}{ Sector } & \multicolumn{3}{c}{ Interruption duration } \\
\cline { 2 - 4 } & $\mathbf{2 \times \mathbf { 1 }} \mathbf{~ \mathbf { i n }}$ & $\mathbf{2 \times 2 0} \mathbf{~} \mathbf{i n}$ & $\mathbf{1 ~ \mathbf { ~ }}$ \\
\hline Commercial & 0.381 & 2.969 & 8.552 \\
Agriculture & 0.06 & 0.343 & 0.649 \\
Residential & 0.001 & 0.093 & 0.482 \\
\hline
\end{tabular}

Table 2. System present CCDF ( $\$ / K W)$ considering the inflation rate.

\begin{tabular}{ccc}
\hline & Interruption duration \\
\hline $1 \mathrm{~min}$ & $20 \mathrm{~min}$ & $1 \mathrm{~h}$ \\
0.0647 & 0.6062 & 2 \\
\hline
\end{tabular}

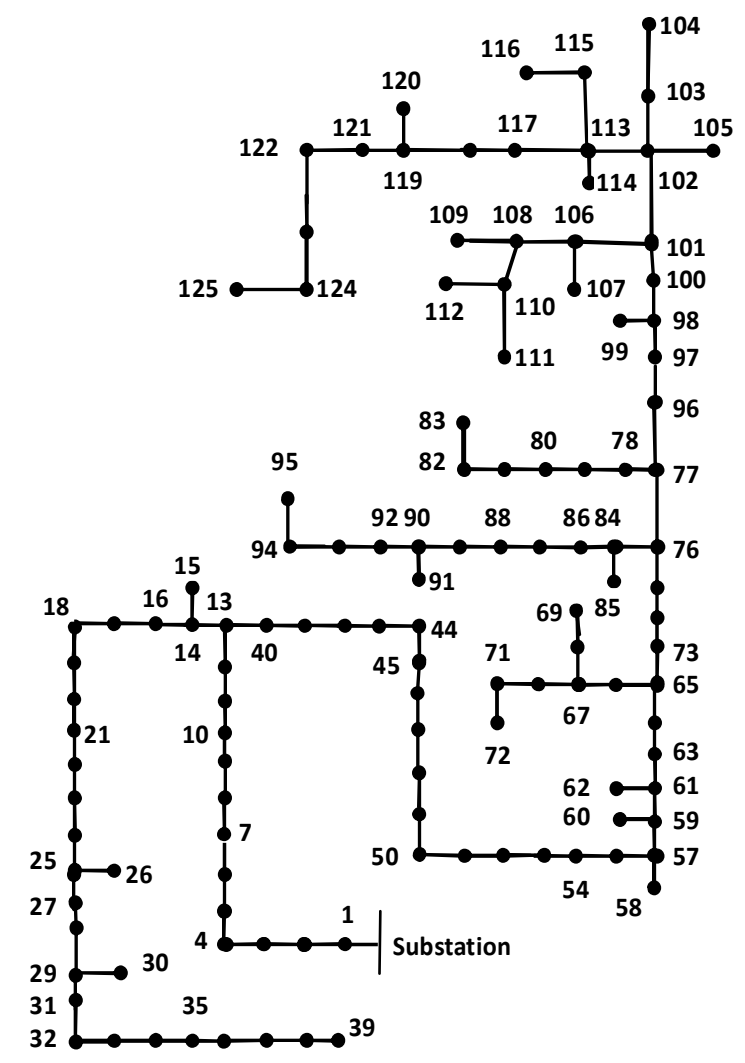

Figure 1. The case study network.

$J_{2}=\sum_{i=1}^{T_{N I}} U_{i} \times C C D F_{i}$

\section{Active power loss}

A significant purpose through utilization of $D G$ in distribution systems is to minimize the total active power loss. Therefore, the third objective function is set as Equation (7):

$J_{3}=\sum_{l=1}^{m} 3 R_{l} I_{l}^{2}$

The objective function is minimized subjected to some specified constraints:
a) $V_{\min } \leq V_{j} \leq V_{\max }$
$\forall j \in N$
b) $\sum P_{D G_{i}} \leq \sum P_{\text {Load }_{i}}$
$\forall i \in N$
C) $J_{\text {peak }}^{i} \leq J_{\text {peak }}^{\text {config-i }}$
$\forall i \in L$
d) $S_{S T} \leq S_{S T}^{r}$
e) $S_{C T}^{i} \leq S^{i, r}{ }_{C T}$

In this work, the backward/forward load flow (Shirmoharmnadi et al., 1998; Eminoglu and Hocaoglu., 2009 ) is employed to calculate branches' currents.

\section{Distribution system under study}

The distribution system under study is the Farhangsara feeder of the Neyshabur city, Iran distribution network as shown in Figure 1 schematically. The radial network includes one 132/20 KV substation (root node) and comprises 125 nodes at normal operation. The case study network has 8.25 MVA installed transformer capacity with 50 scattered transformers from $50 \mathrm{KVA}$ up to $500 \mathrm{KVA}$ and provides 4.84 MVA power demand at present. The network also supplies 5 type of domestic, commercial, domestic-commercial, well (agricultural and water supply) and street lighting loads. Natural gas distribution network is available close to the any bus. The network totally has $19.73 \mathrm{Km}$ length and has been constructed from Dog, Mink, and Fox configurations. The aim is to supply the network at the horizon year (10 year). With respect to forecasted load growth of the network, it should be served about 7.95 MVA at the horizon year.

\section{Multi-objective optimization}

In order to show the effectiveness of the proposed algorithm in finding of solutions, a developed program in $M A T L A B$ environment is used.

Among the various DG technologies, five common types are considered in this paper regarding their size ranges, costs and types (Willis and Scott, 2000; Hamilton, 2003). Since the case study system serves a 
Table 3. Cost and performance characteristics of DGs.

\begin{tabular}{clcccccc}
\hline No. & Type & Fuel & Size $(\mathbf{K W})$ & PF & Cost $\mathbf{( \$ )}$ & O\&M (\$/yr) & Fuel efficiency \\
\hline 1 & Internal combustion & Nat.gas & 275 & 0.8 & 119,426 & 5,032 & 26 \\
2 & Micro-Turbine & Nat.gas & 175 & 0.9 & 131,500 & 1400 & 33 \\
3 & Fuel cell & Nat.gas & 210 & 0.8 & 336,000 & 18000 & 43 \\
4 & Internal combustion & Nat.gas & 50 & 0.8 & 22,000 & 1,150 & 31 \\
5 & Micro-Turbine & Nat.gas & 250 & 0.9 & 176,000 & 2,100 & 32 \\
\hline
\end{tabular}

Table 4. SPEA parameters.

\begin{tabular}{ll}
\hline Parameter & Value \\
\hline Iteration & 50 \\
Population size & $\mathrm{N}=80$ and $\mathrm{N}^{\prime}=20$ \\
Chromosome coding & Real-code \\
Selection & roulette wheel \\
Recombination & Single-point crossover \\
Mutation & Discrete with probability of 0.035 \\
\hline
\end{tabular}

part of city, DG allocation has some environmental limitations. Gas turbine technology is known to be environmentally friendly and it produces the least pollution and noise compared to other fossil fuels. In addition, natural gas network is available through the pipeline. Therefore, it seems to be better using of natural gas DG units. Table 3 lists the candidate DGs. It is notable that all DG units are modeled as $P Q$ sources.

Many existent problems need simultaneous optimization of different and usually competing objectives. In this case, there is a set of optimal solutions instead of a single one. These sets are known as Pareto Optimal Sets (POS). In the absence of any further information, none of these POS could be said to be better than the others (Fonseca and Fleming, 1995).

An unconstrained Multi-objective Optimization Problem (MOP) can be generally described as:

Minimize: $f_{i}(x), \quad i=1, \ldots, m$

Where $f(x)$ is a vector of the objective functions and $x=\left(x_{1}, x_{2}, \ldots x_{n}\right)$ is the decision vector.

A solution $x_{1}$ in the search space is non-dominated if there exists no other $x_{2}$ such that for all values of $i$, $f_{i}\left(x_{2}\right) \leq f_{i}\left(x_{1}\right)$ and at least for one $i, f_{i}\left(x_{2}\right)<f_{i}\left(x_{1}\right)$. The set of all non-dominated solutions is called POS and the set of the corresponding values of the objective functions is called Pareto Optimal Front (POF) or simply Pareto front.

Evolutionary Algorithms (EAs) are suitable approaches to solve the MOPs because they process a set of solutions in parallel. In the recent decades, there has been a growing interest in solving MOPs using EAs.
There are three major types of EAs (Fonseca and Fleming, 1995), plain aggregating approaches which often artificially combine, or aggregate the objectives to a scalar function (Syswerda and Palmucci, 1991; Jakob et al., 1999), population-based non-Pareto approaches which optimize the objectives separately and search for POF in a single run (Horn and Nafpliotis, 1993; Hajela and Lin, 1992; Schaffer, 1985) and Pareto-based approaches which are advanced and new techniques (Zitzler and Thiele, 1999; Srinivas and Deb, 1994).

\section{SPEA}

The SPEA, a novel Pareto-based EA, is used in this paper. This method takes benefit from many features of some other approaches and includes the following major steps (Zitzler and Thiele, 1999):

\section{SPEA algorithm}

1. Produce an initial population $P$ and create the empty external non-dominated set $Q$.

2. Paste non-dominated members of $P$ into $Q$.

3. Remove all the solutions within $Q$, which are covered by any other members of $Q$. If the number of externally stored non-dominated solutions exceeds a given maximum $N^{\prime}$, prune $Q$ by means of clustering.

4. Calculate the fitness of all individuals in $P$ and $Q$.

5. Use binary tournament selection with replacement and select the individuals from $P$ and $Q$ until the mating pool is filled.

6. Apply crossover and mutation operators as usual.

7. If the maximum number of generations is reached, then stop, else go to step 2.

Fitness evaluation is also performed in two steps. First, the individuals in the external non-dominated set $Q$ are ranked. Then, the individuals in the population $P$ are evaluated (Zitzler and Thiele, 1999).

The type of DG units and their location compose the decision vector. The SPEA is employed to solve the problem, with the population size of 100 . The Pareto front size is tuned to 20 individuals. The $4: 1$ ratio between population and front size is selected as suggested in (Zitzler and Thiele, 1999) Table 4 gives more describtion of SPEA parameters. 




Figure 2. Estimated voltage profile of the system buses in the horizon year.

\section{Particle swarm optimization (PSO)}

In the present paper, as mentioned, particle swarm optimization algorithm is the second EA which is used to solve the DG allocation problem. Its key concept is that potential solutions are flown through hyperspace and are accelerated towards better or more optimum solutions. It lies somewhere on between evolutionary programming and the genetic algorithms. Some of the features of PSO are adaptability, diverse response, proximity, quality, and stability (Clerc and Kennedy, 2002). There are three versions of PSO: real, binary and discrete codifications. As the decision variables of the present problem are of discrete type, hence, Discrete Particle Swarm Optimization (DPSO) method is used in this paper (Shayeghi et al., 2010).

\section{RESULTS AND DISCUSSIONS}

The following cases are discussed subsequently:

a) The system performance without any DG

b) Conventional planning

c) Optimization of the power generation cost and the system power loss $\left(J_{1}\right.$ and $\left.J_{3}\right)$

d) Optimization of the both power generation cost and interruption cost $\left(J_{1}\right.$ and $\left.J_{2}\right)$

\section{System performance without any DG}

To have a better view of the system performance, voltage profile is plotted in Figure 2. As seen, the voltage magnitudes in some buses are lower than the standard value (0.95 PU), which may damage the customers. Also, the power interruption cost is 580 USD.

\section{Traditional planning}

Traditional long term planning offers a perspective plan for horizon period year-wise, to meet the anticipated load growth and forecasted load under planning criteria and standards of distributed networks. Usually, the system improvement is done by augmentations, reconfiguration (bifurcation or trifurcation, etc.), replacement and reinforcement of the feeders with poor performance. In addition, any transformer is considered to specify its capacity with spatial forecast of energy, power demand, and existing load. Then a decision can be made to strengthen and/or replace the transformer.

In addition, sometimes it is required to install some shunt capacitor banks and voltage regulator or change the transformers tap within the network to compensate voltage drop and to have a smooth voltage profile.

Based on the forecasted loads and their natures, feeders and transformers' free capacity, criteria and standards of the distribution networks, the following decisions are made:

1. There is a significant voltage drop at the horizon year (Figure 2), within root node up to node no. 12 and node no. 40 up to node no. 65. The feeder in these sections is created by Dog configuration. Thermal analysis shows that there is no problem using this type of conductor but voltage drop and power loss put emphasis on changing the configuration or bundling of existing conductor. To avoid interruption throughout the network, it would be better to strengthen this study with another Dog conductor. 
Table 5. Transformers price.

\begin{tabular}{cc}
\hline Capacity (KVA) & Price (\$) \\
\hline 50 & 2500 \\
75 & 3050 \\
100 & 3400 \\
125 & 3800 \\
200 & 4500 \\
250 & 5000 \\
315 & 5500 \\
\hline
\end{tabular}

In general, bundling cost includes contractor fee and conductor cost. Contractor fee (USD) is assumed $\$ 2500$ $/ \mathrm{km}$. Also conductor cost is determined $\$ 1.6 / \mathrm{km}$.

2. Substation tap changer can help voltage profile to rise without unacceptable overvoltage at customer transformer, whereas, the nearest customer's transformer is connected to bus no. 14. The substation tap changer has a regulation range between $-4 \%$ and $+4 \%$.

3 . Some transformers need to be replaced to meet the forecasted load growth.

Considering the installed transformers, 18 transformers (36\% of all transformers) must be replaced or the subjected loads must be descended via new transformer installation near to the fully loaded transformers.

Final decision is made by installing 5 new transformer units and replacing other 13 transformers. Replacements and new installations are determined to need $\$ 500$ and $\$ 700$ charges for contractor cost, $\$ 3050$ and $\$ 200$ for additional and miscellaneous charges respectively. Table 5 lists distribution transformers prices. It should be mentioned that the scrap value of any transformer is set to $60 \%$ of a new transformer.

$10 \mathrm{~h}$ is presupposed to replace a fully loaded transformer, and $1 \mathrm{~h}$ to energize new installed transformer. According to these assumptions, total cost of transformer replacement and new installation are brought in Table 6.

Figure 2 shows the voltage profile in the horizon year, as a result of traditional planning implementation. Minimum voltage amplitude is $0.958 \mathrm{PU}$ and for the nearest customer transformer to the substation (node no.14), voltage amplitude is equal to $0.989 \mathrm{PU}$.

In addition, active power loss will be reduced from 822 to $423 \mathrm{~kW}$. This loss reduction leads to $6 \%$ active power loss in the case study system.

\section{Optimization of both the DG's annual cost and the power loss}

Using the results obtained in System performance without any DG and considering practical limitations, some commercial and residential loads are selected to install candidate DGs. The associated nodes are given in Table 7. It is notable that some candidate nodes may not be chosen to install DG units on them.

A lifetime of 20 years is considered for the candidate DGs to facilitate the problem. The $L C C$, initial $M O E$ and annual MOE are assumed to be $\$ 10000, \$ 19000$, and $\$ 1000$ respectively. Also IR is supposed $10 \%$.

At the first step, the planning objective is the minimization of both the annual energy cost and active power loss. The SPEA and PSO algorithms are employed to find the best solution and their results are compared with each other. The population size and iteration number for both algorithms are equal. Figures 3 and 4 present the SPEA and POS convergence trend respectively. The POF is plotted in Figure 5 against the result of PSO. The POF is composed of 20 optimum solutions, distributed in the two-dimensional objective functions space. Each point in POF, Figure 5, represents an optimal solution for planning scenario. It means that the POF gives the designer more flexible options. The range of power loss and energy cost variations is from 650 to $50 \mathrm{~kW}$ and from $0.5 \times 10^{5}$ to $11.5 \times 10^{5}$ USD respectively from optimal point of 1 to 20 . To have a better sight, 5 points are selected and detailed in Table 7. This table shows the type and size of installed DGs on the candidate nodes. The first plan comprises just 13 small DG units with the least energy cost. In the plan no. 20, as expected, except $93^{\text {th }}$ one, all buses are equipped with a DG of almost large size. In this plan, the cost is almost fifteen times greater than plan 1 while power loss is thirteen times smaller. Figure 5 shows that the PSO result is very close to the POF and it can be considered as a POF. The objective function of PSO is defined as $a \times J_{1}+b \times J_{3}$ where $a=b=1$. Changing a and/or $b$, the PSO result might shift on POF. Using POS, total interruption cost is computed and plotted in Figure 6.

To investigate the voltage profile of the test system, Figure7 is plotted. Figure 8 shows the lowest voltage magnitude of the system corresponding POF points. Comparing Figure 8 with Figure 2, minimum voltage of all plans is better than the case that there is no DG. The last 11 plans, which own the higher costs, have standard voltage level through the system. It is clear that there is a rational linkage between the energy cost and voltage drop. Also, as it is seen, sometimes, increasing the financial investment from a plan to another does not result in considerable voltage improvement. Another attractive result is deterioration of the system voltage from plan 12 to 13 . Although plan 13 provides more cost than plan 12, but its minimum voltage is less than the plan 12.

\section{Optimization of both the DG's annual cost and interruption cost $\left(\mathrm{J}_{1}\right.$ and $\left.\mathrm{J}_{2}\right)$}

In this case, the DG installation cost and the interruption cost are minimized by both SPEA and PSO algorithms 
Table 6. Conventional planning cost explanation.

\begin{tabular}{lcc}
\hline & Replacement & New installation \\
\hline Trans & 5 cases & 13 cases \\
Contractor cost $(\$)$ & $5^{\star} 700$ & $13^{*} 500$ \\
Miscellaneous charges $(\$)$ & $5^{\star} 3050$ & $13^{*} 200$ \\
Trans. Price $(\$)$ & $3^{\star} 5500,2^{\star} 5000$ & $6^{\star} 3050,6^{*} 3400,1^{\star} 3800$ \\
Scrap value of transformer $(\$)$ & 13500 & ---- \\
Interruption cost $(\$)$ & 8199 & 6843 \\
Total cost $(\$)$ & 39949 & 40083 \\
& Marginal cost of traditional planning $(\$) 80032$ \\
\hline
\end{tabular}

Table 7. Selected Pareto optimal front

\begin{tabular}{|c|c|c|c|c|c|c|c|c|c|c|c|c|c|c|c|c|c|c|c|c|c|c|c|c|c|c|c|c|c|c|c|}
\hline \multirow{2}{*}{ Plan } & \multicolumn{31}{|c|}{ Node number } \\
\hline & 47 & 50 & 55 & 61 & 64 & 66 & 69 & 70 & 71 & 72 & 78 & 83 & 85 & 86 & 88 & 91 & 93 & 97 & 99 & 105 & 107 & 109 & 111 & 112 & 114 & 116 & 118 & 119 & 122 & 124 & 125 \\
\hline 1 & 4 & 1 & 4 & 4 & 0 & 0 & 4 & 0 & 0 & 4 & 0 & 4 & 0 & 4 & 0 & 4 & 0 & 0 & 0 & 0 & 4 & 0 & 5 & 0 & 0 & 0 & 4 & 0 & 0 & 0 & 4 \\
\hline 5 & 4 & 1 & 4 & 0 & 2 & 0 & 1 & 2 & 0 & 1 & 0 & 4 & 1 & 4 & 0 & 4 & 0 & 0 & 0 & 1 & 4 & 0 & 5 & 0 & 0 & 0 & 4 & 0 & 0 & 0 & 4 \\
\hline 10 & 1 & 2 & 1 & 5 & 4 & 4 & 4 & 0 & 0 & 1 & 0 & 4 & 0 & 0 & 0 & 2 & 0 & 1 & 1 & 0 & 1 & 0 & 5 & 0 & 1 & 5 & 3 & 1 & 1 & 1 & 5 \\
\hline 15 & 1 & 0 & 5 & 2 & 0 & 1 & 1 & 2 & 5 & 4 & 1 & 1 & 2 & 3 & 5 & 5 & 1 & 1 & 0 & 5 & 1 & 1 & 5 & 5 & 1 & 5 & 1 & 5 & 2 & 1 & 0 \\
\hline 20 & 1 & 3 & 3 & 1 & 2 & 2 & 1 & 2 & 5 & 1 & 1 & 1 & 2 & 3 & 5 & 3 & 0 & 1 & 2 & 5 & 5 & 1 & 5 & 5 & 1 & 5 & 3 & 1 & 1 & 5 & 5 \\
\hline PSO & 4 & 0 & 5 & 0 & 0 & 5 & 0 & 0 & 0 & 2 & 2 & 5 & 1 & 4 & 1 & 1 & 0 & 0 & 0 & 0 & 0 & 4 & 0 & 1 & 0 & 4 & 4 & 1 & 4 & 0 & 0 \\
\hline
\end{tabular}

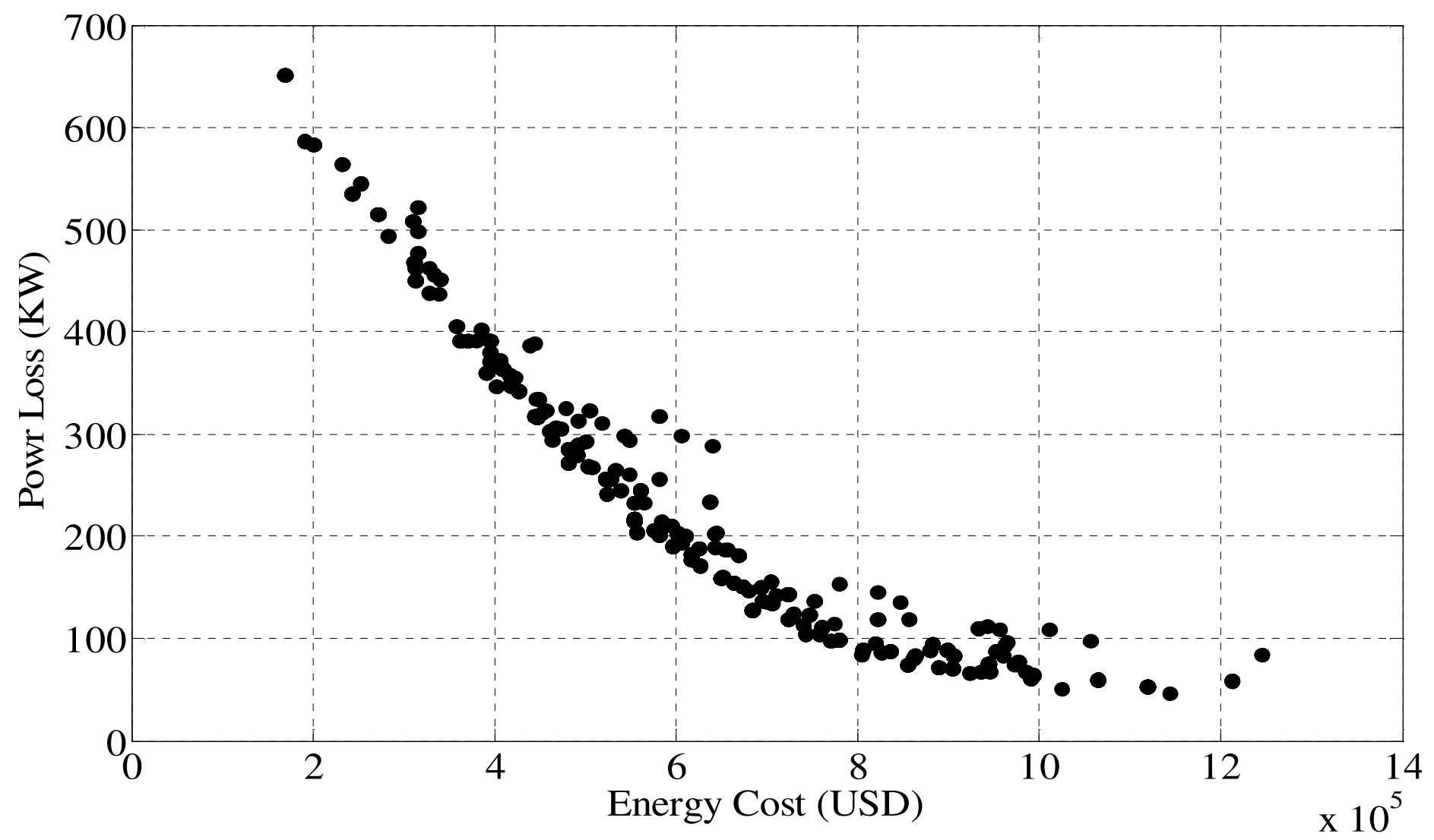

Figure 3. The convergence trend of SPEA. 


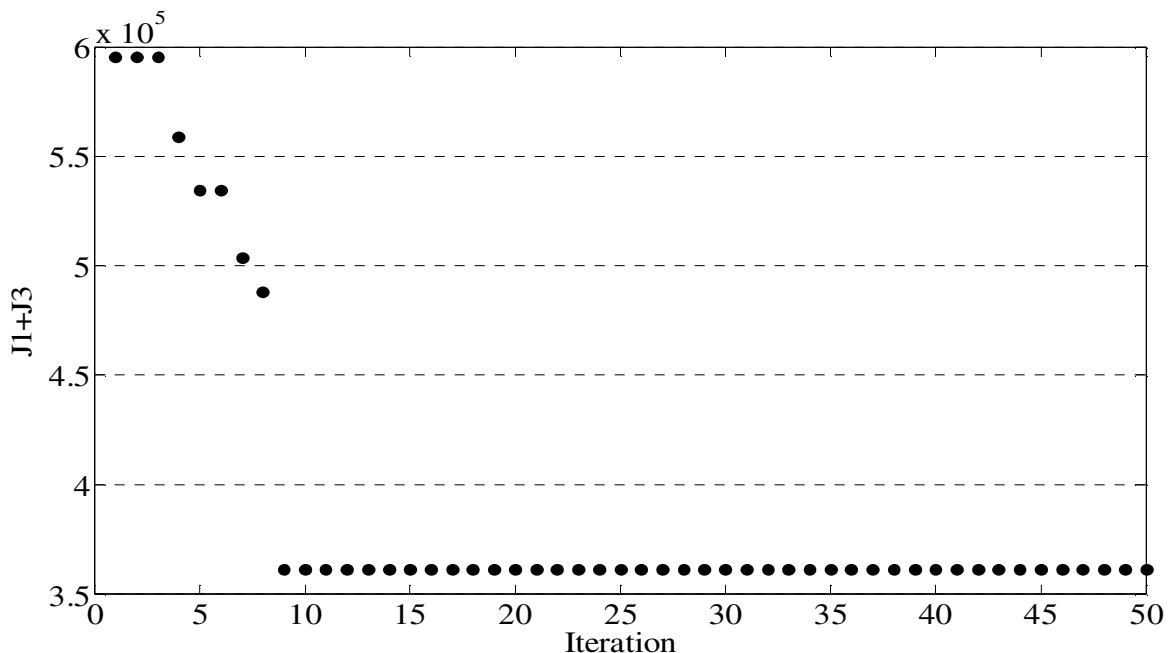

Figure 4. The convergence trend of PSO.

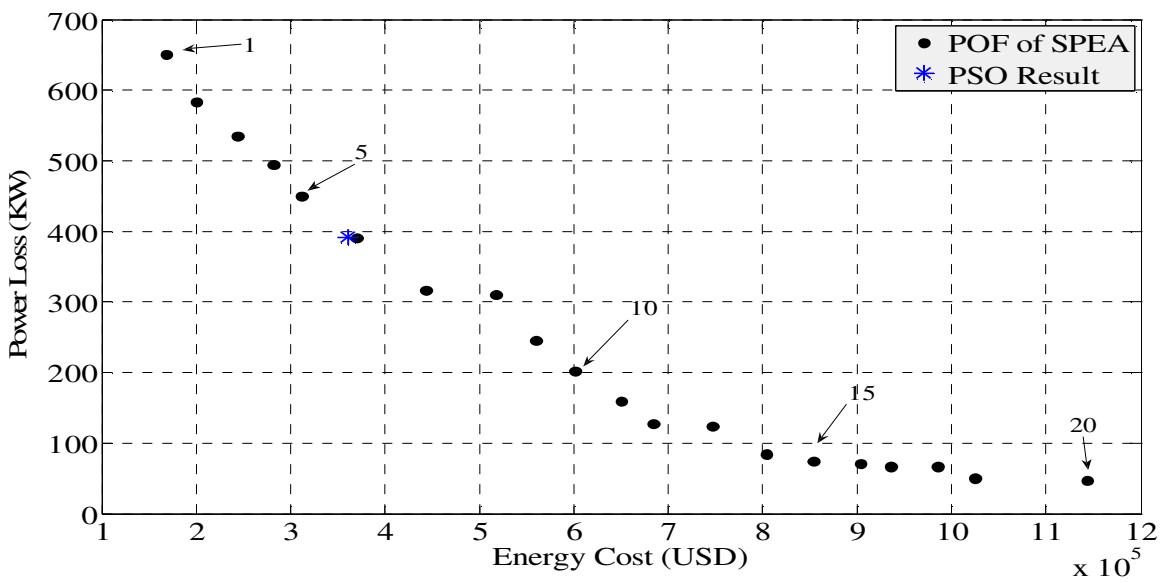

Figure 5. Cost-loss Pareto optimal front.

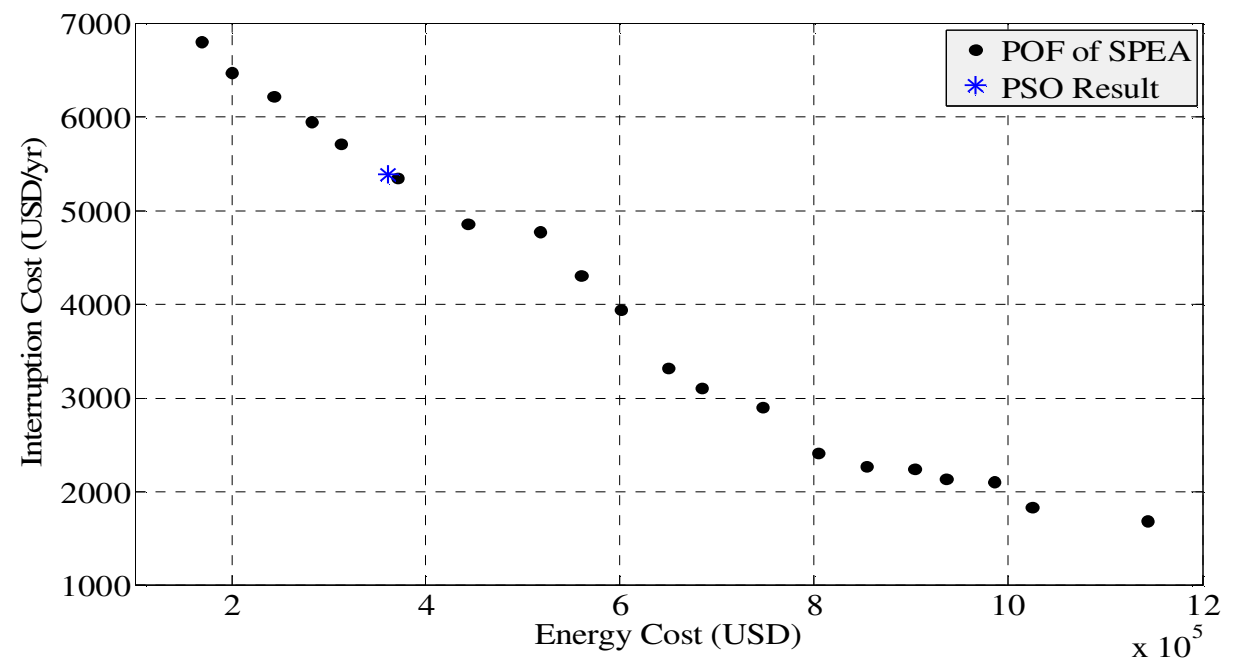

Figure 6. Total interruption costs for resulted plans 


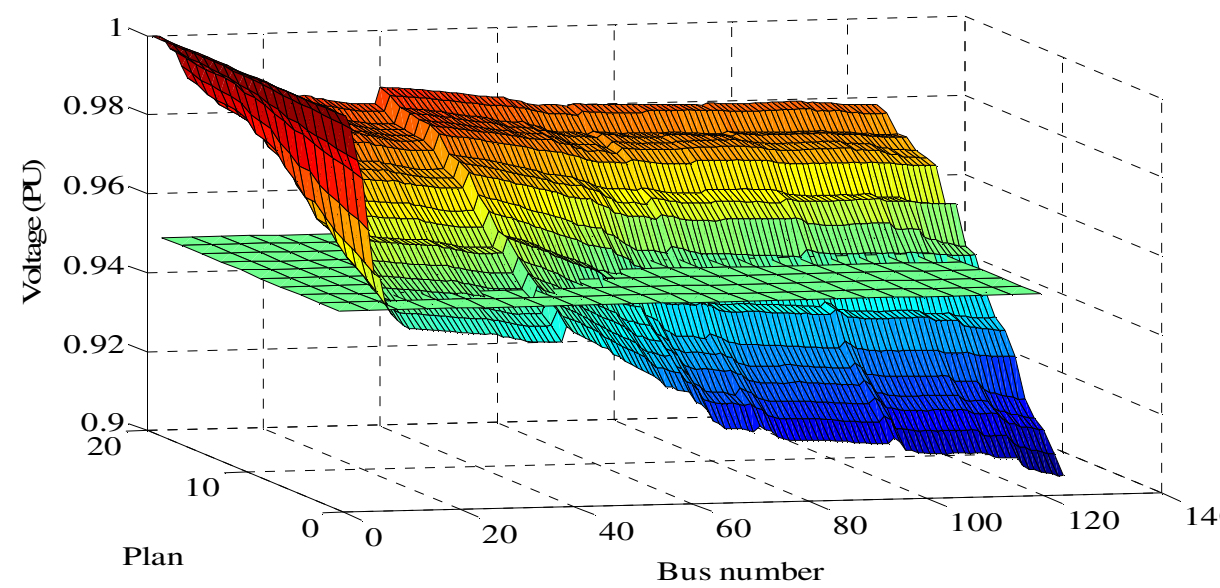

Figure 7. Voltage profile of the system.

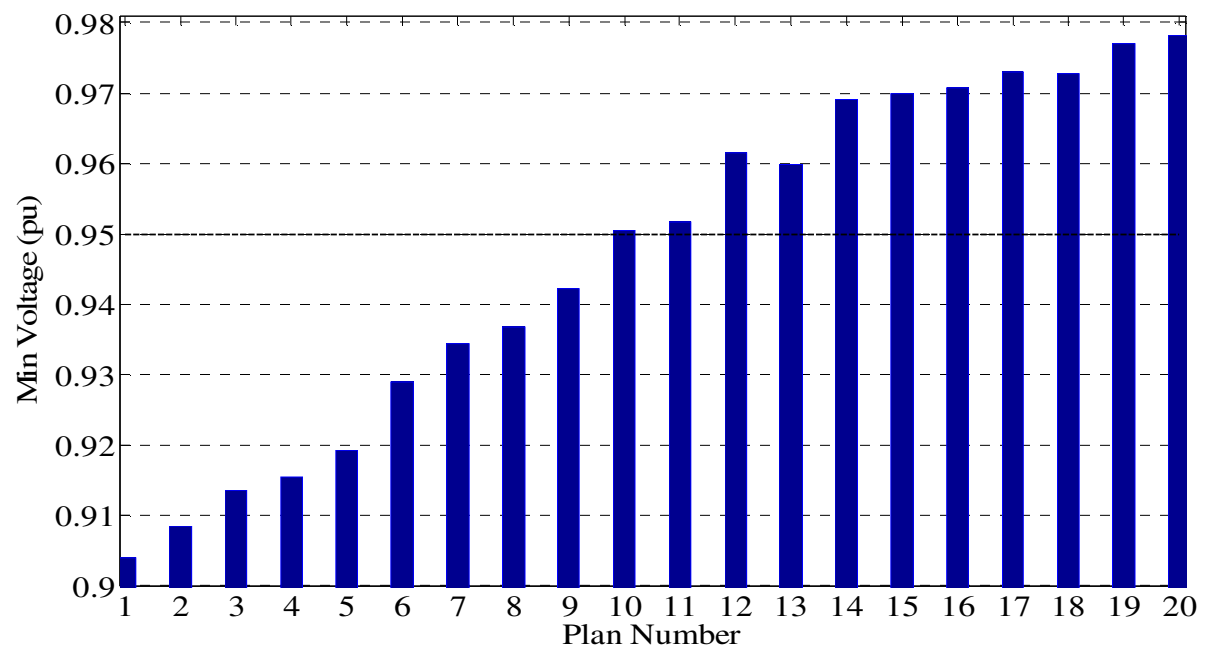

Figure 8. The system minimum voltage values in members of the POF.

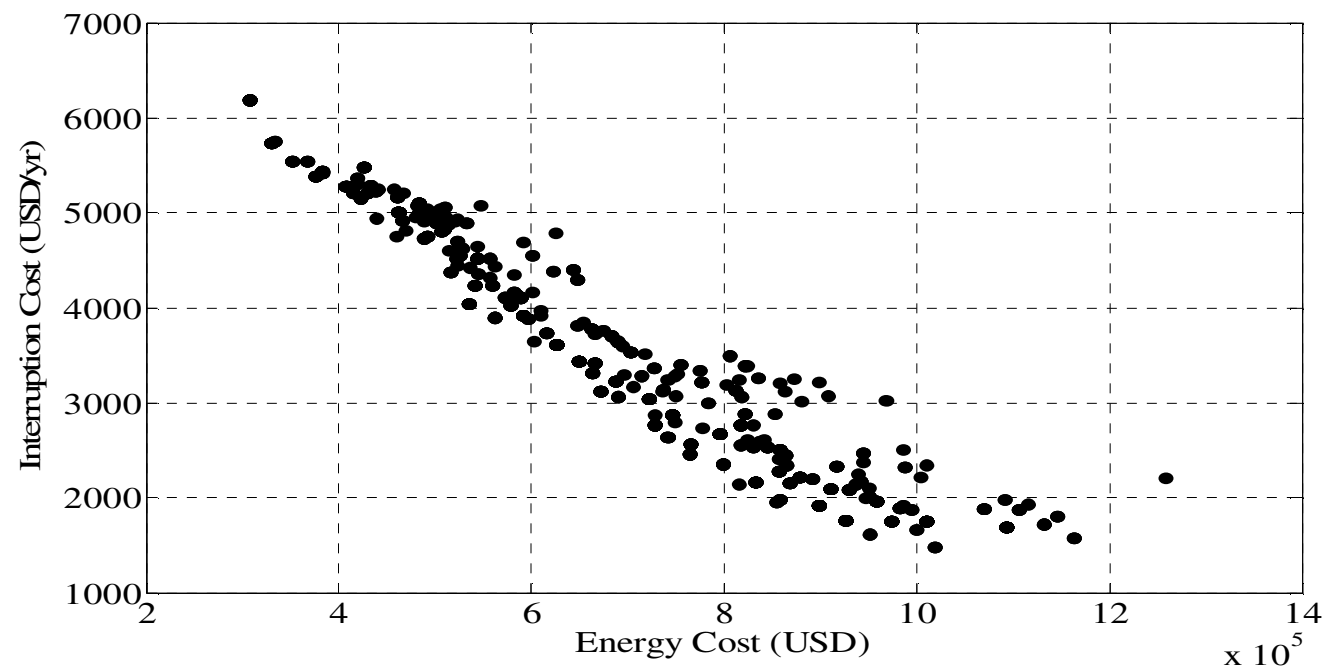

Figure 9. The convergence trend of SPEA. 


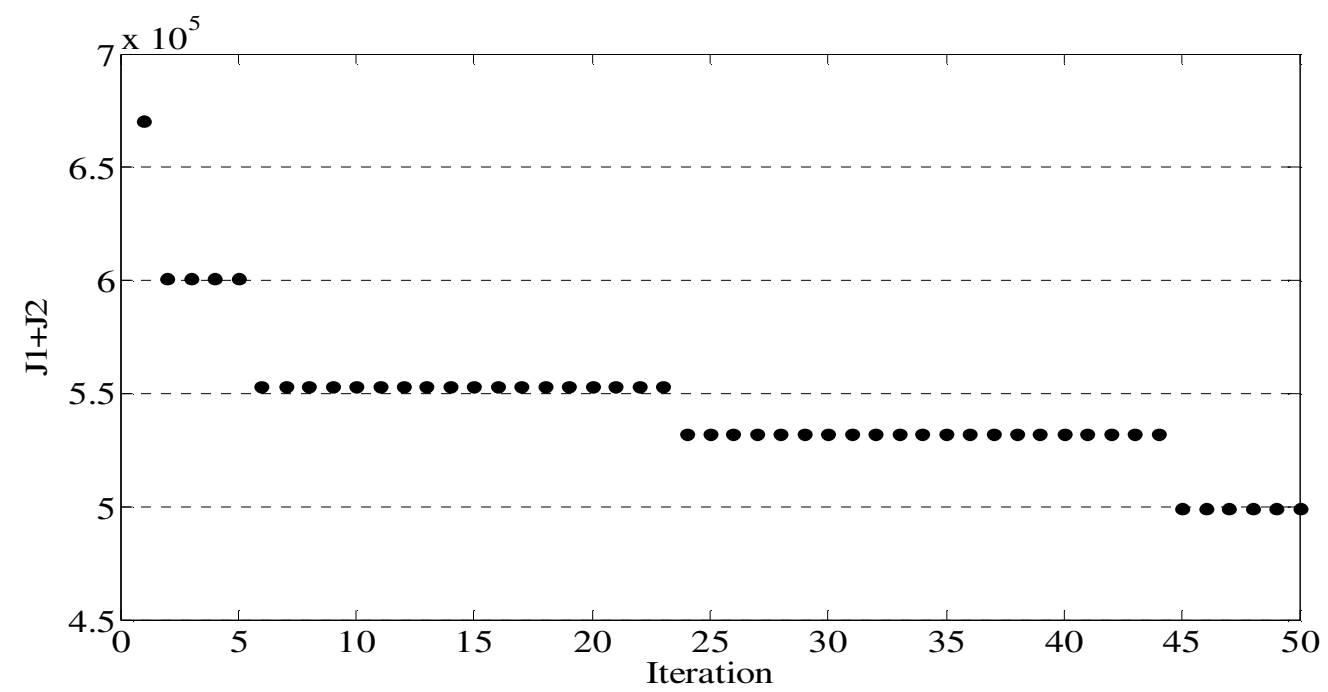

Figure 10. The convergence trend of PSO.

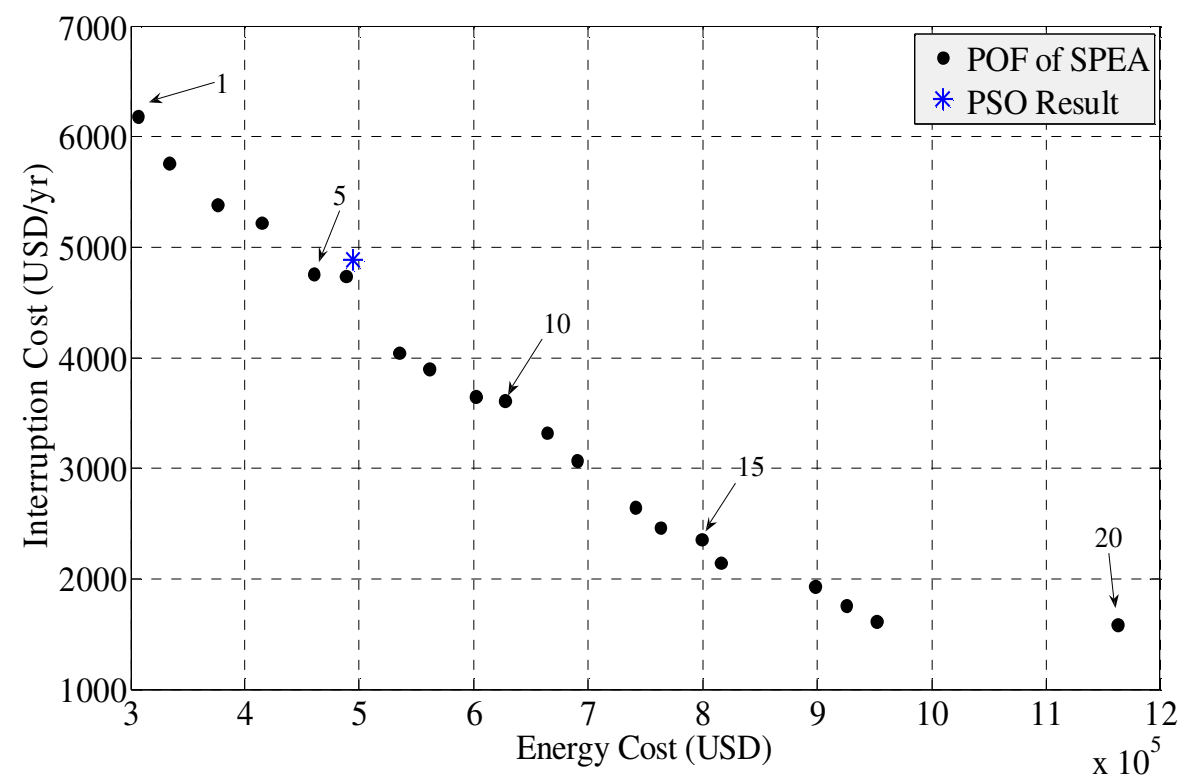

Figure 11. Energy cost-interruption cost Pareto optimal front.

and the results are investigated. Figures 9 and 10 illustrate the convergence trend of SPEA and PSO, respectively. The corresponding results are shown in Figure 11. Power loss is computed for the POS and plotted against energy cost in Figure 12. As shown, like the Figure 5, the result of PSO can be supposed by a member of POF. For more analysis, like the previous case, the details of 5 plans are represented in Table 8. Comparing Figure 6 with 11 and 5 with 12, it is obvious that for a given energy cost in the first plans of POF, interruption cost and power loss in section 3.3 have lower value. This comparison does not display any clear difference for the last plans.

Evaluation of Tables 7 and 8 clarifies some differences and some similarities. For example, plan 20 which have almost the same energy cost, power loss and reliability, have different DG proposal in cases in Optimization of both the DG's annual cost and the power loss and Optimization of both the DG's annual cost and interruption cost $\left(J_{1}\right.$ and $\left.J_{2}\right)$. In this plan, all candidate buses are equipped with DGs except one bus which is different in Tables 7 and 8 . Also, PSO solution has different attributes in two cases. This is rational, because it is different in the sense of energy cost, power loss and 


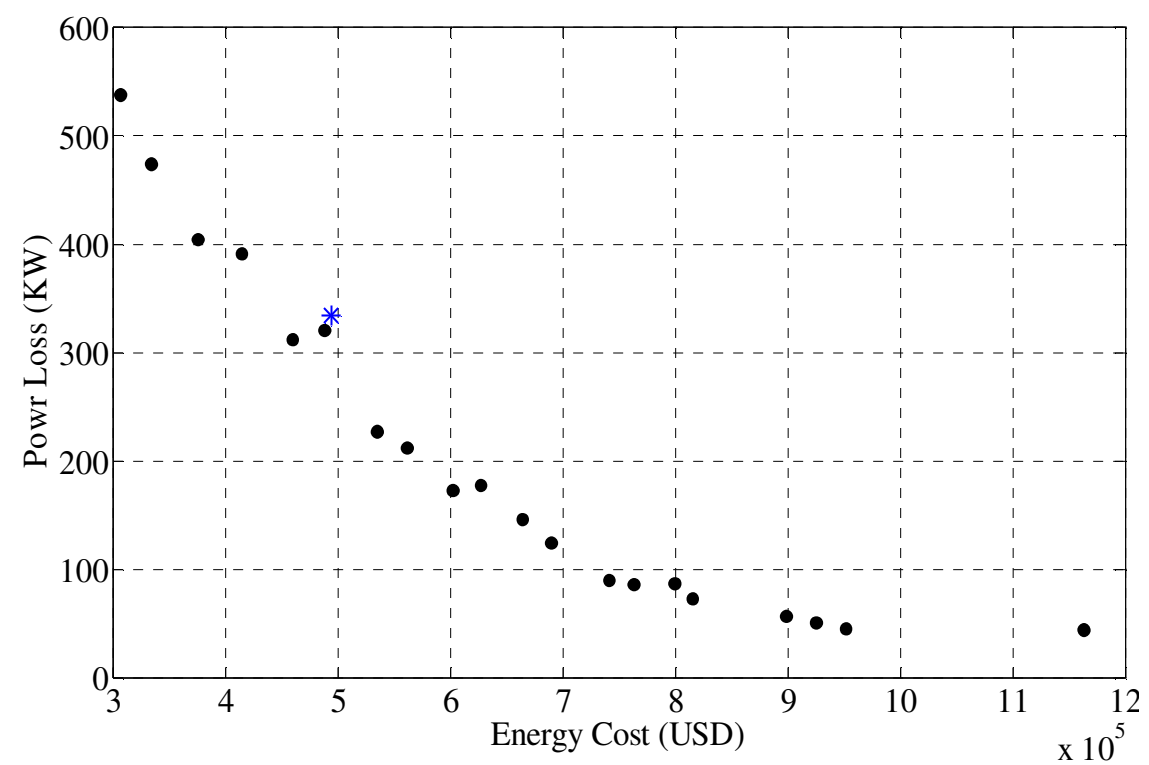

Figure 12. Power loss-energy cost front.

Table 8. Selected Pareto optimal front.

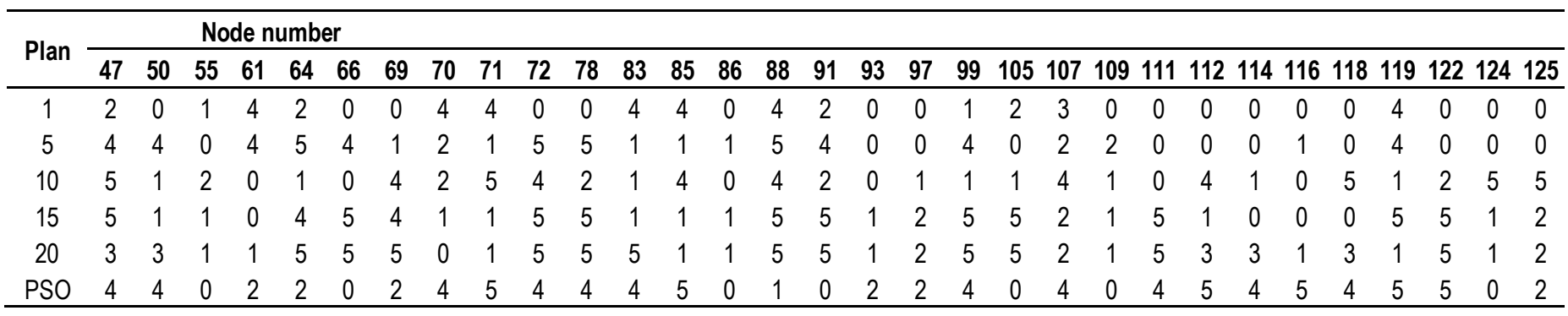

reliability in Optimization of both the DG's annual cost and the power loss and Optimization of both the DG's annual cost and interruption cost $\left(\mathrm{J}_{1}\right.$ and $\left.\mathrm{J}_{2}\right)$.

Figure 13 presents the system voltage profile for all plans. Minimum voltage values of the system buses are extracted and shown in Figure 14 respectively. Unlike the part in Optimization of both the DG's annual cost and the power loss, twelve plans voltages are in the standard range. This figure clearly illustrates relation of the monetary investment and voltage profile improvement.

\section{DISCUSSIONS}

By comparing the results, as expected, it is obvious that conventional system planning is very cheaper than DG placement. So, it may seem that $D G$ is not a suitable choice, but some points need to be noticed:

1. DG units, if placed in proper situations, depending on the financial investment, improve reliability level and compensate some of customer damages during power interruption. In addition, it reduces system power losses as much as $70 \%$.

2. Conventional planning scheme, consisted of feeder reinforcement and transformers replacement, do not improve the reliability very much and reduces power loss up to $50 \%$.

3. With DG units, in the case of transformer failure, some of loads could be fed locally.

4. DISCO owned DG units has bidding that is more flexible in electricity markets. Moreover their output heat could be used and make useful energy again (CHP).

5 . In the conventional planning scheme, considering load growth, supplied power from substation transformer should be increased. This will raise its loading and necessity to install new substation. However, this cost is considered in DG planning expense, but within some years, associated budget will be compensated by reliability improvement and loss reduction costs.

6. DG penetration through the system increases network stability against the terroristic attack.

7. The presented multi-objective planning method proposes a number of optimal solutions which seems 


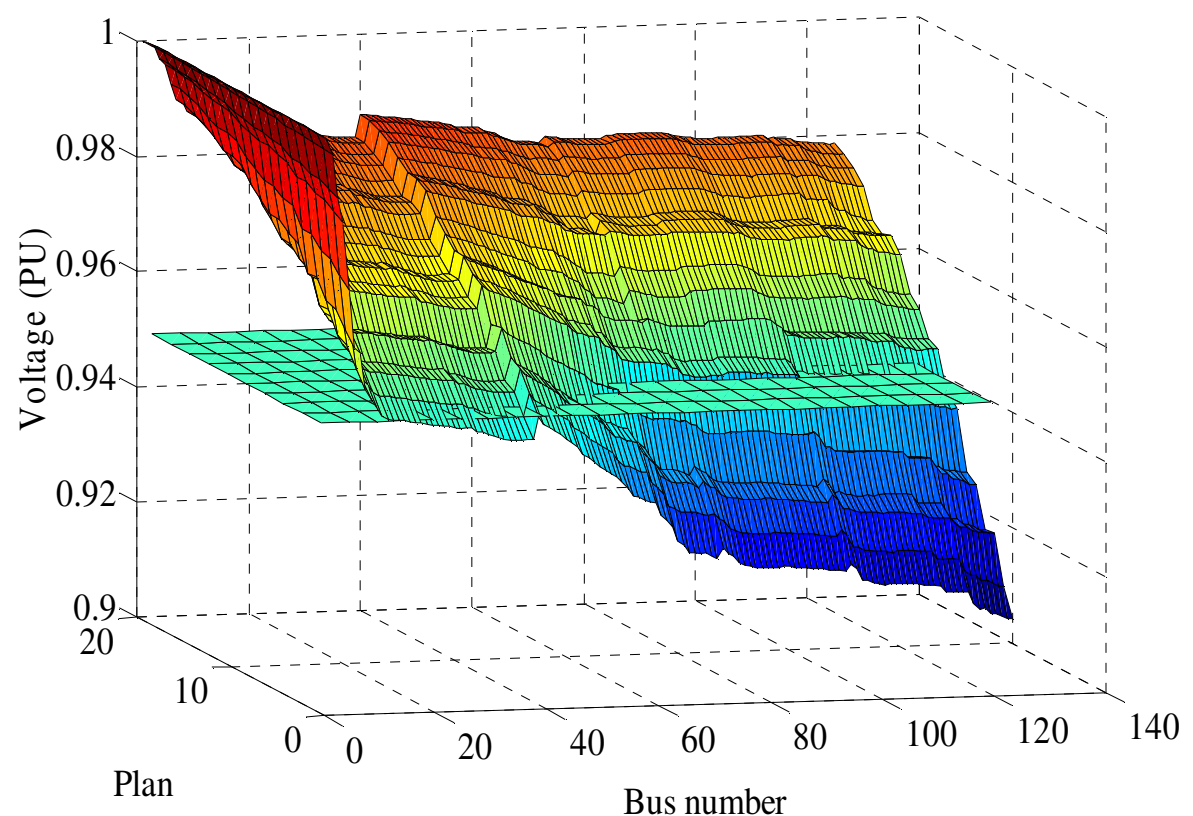

Figure 13. Voltage profile of the system.

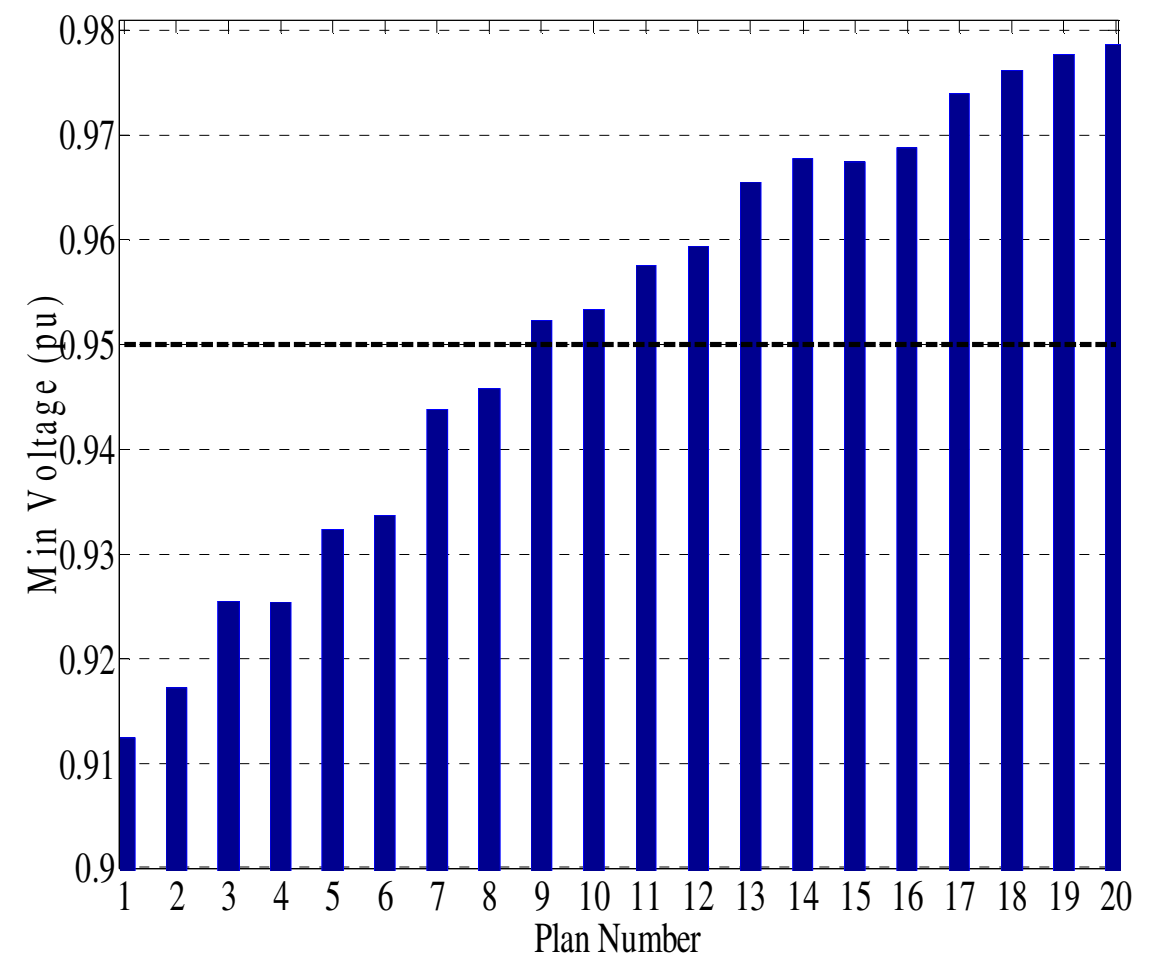

Figure 14. The system minimum voltage values in members of the POF.

to be more flexible than conventional one.

8. Minimum achievable voltage in conventional method is 0.958 , while some of the proposed optimal plans have better voltage profile.

\section{Conclusion}

This paper proposed flexible optimal DG planning scheme for distribution network using SPEA. Marginal 
cost of DG installation, reliability, and power loss were the optimization objective functions to be minimized. Some well-known models were employed to show these objectives carefully. A test distribution network with high voltage drops at end nodes was used to study the DG placement problem. Two cases were considered: 1) DG cost and power loss, and 2) DG cost and interruption cost minimization. The SPEA and PSO were employed to solve the problem and find the optimum solutions. The SPEA optimized the objectives separately and since the objectives were in conflict with each other, SPEA produced a set of optimum solutions named as POF. Then sum of the objective functions were optimized by PSO in each case. The results comparison proved that SPEA provides a set of plans in a single run so that the result of PSO is a member of that set. Also, it was shown that the optimization of the two aforementioned sets of objectives result in some similarities and some differences in their voltage profiles and DG placement. In addition, a comparison with conventional distribution system planning was done. The results illustrated higher marginal cost in the case of using DG units, but more reliability and lower power loss compared to traditional planning.

\section{ACNOWLEDGMENT}

The authors thank the Khorasan Razavi Electrical Distribution Company (KREDC), Ministry of Niroo, Islamic Republic of Iran, as this research was made using their documents and information.

\section{REFERENCES}

Ali SA, Wacker G, Billinton R (1999). Determination and use of sector and composite customer camage functions. Pro. IEEE Canadian Conf. Elect. Comput. Eng., 3: 1483-1488.

Billinton R, Allan RN (1996). Reliability Evaluation of Power Systems, Second Edition, Plenum Press, New York. Chpt. 13.

Clerc M, Kennedy J (2002). The particle swarm-explosion, stability, and convergence in a multidimensional complex space. IEEE Trans. Evolut. Comput., 6: 58-73.

Distributed Generation, Penetration Instruction (2008). Niroo Ministry, Islamic Republic of Iran, No. 52504/350, 2008.

Doty S, Turner WC (2009). Energy Management Handbook, $7^{\text {th }}$ Edition, Fairmont Press.

Eminoglu U, Hocaoglu MH (2009). Distribution systems forward/ backward sweep-based power flow algorithms: a review and comparison study. Elect. Power Compon. Syst., 37: 91-110.

Fonseca CM, Fleming PJ (1995). An overview of evolutionary algorithms in multiobjective optimization. Evol Comput., 3: 1-16.

Gandomkar M, Vakilian M, Ehsan M (2005). A genetic-based tabu search algorithm for optimal DG allocation in distribution networks. Elect. Power Compon. Syst., 33: 1351-1362.

Gil HA, Joos G (2008). Models for quantifying the economic benefits of distributed generation. IEEE Trans. Power Syst., 23: 327-335.
Hajela P, Lin CY (1992). Genetic search strategies in multicriterion optimal design. Structural and Multidisciplinary Optimization, Springer., 4: 99-107.

Hamedani Golshan ME, Arefifar S Ali (2009). Optimal allocation of distributed generation and reactive sources considering tap positions of voltage regulators as control variables. European Trans. Elect. Power, 17: 219-23.

Hamilton S (2003). The Handbook Of Microturbine Generators, first edition, Pennwell Books (Jun 2003), Ch. 4

Horn J, Nafpliotis N (1993). Multiobjective optimization using the niched pareto genetic algorithm. Proc. IEEE Conf. Evol. Comput., 1: 82-87.

Jakob W, Gorges-Schleuter M, Blume C (1992). Application of genetic algorithms to task planning and learning. Proc. PPSN-II Conf., Brussels, Belgium, pp. 291-300.

Kim KH, Song KB, Joo SK, Lee YJ, Kim JO (2008). Multiobjective distributed generation placement using fuzzy goal programming with genetic algorithm. European Trans. Elect. Power, 18:217-230.

Lee SH, Park JW(2009). Selection of optimal location and size of multiple distributed generations by using kalman filter algorithm. IEEE Trans. Power Syst., 24: 1393-1400.

Niknam T, Ranjbar AM and Shirani AR (2003). Impact of distributed generation on volt/var control in distribution networks. IEEE Power Tech Conf., 3: 3-7.

Pansini AJ (2007). Electrical Distribution Engineering, $3^{\text {rd }}$ edittion, CRC Press, Taylor \& Francis Ltd, Part 2.

Schaffer JD (1985). Multiple objective optimization with vector evaluated genetic algorithms. Proc. first International Conf. Gen. Algorith., 93100.

Shayeghi H, Mahdavi M, Bagheri A (2010). Discrete PSO algorithm based optimization of transmission lines loading in TNEP problem. Energy Conver. Manage., 1125(51): 112-121.

Shirmoharmnadi D, Hong HW, Semlyen A and Luo GX (1998). A compensation-based power flow method for weakly meshed distribution and transmission networks. IEEE Trans. Power Syst., 3: 753-762.

Short W, Packey DJ, Holt TA (1995). Manual for the economic evaluation of energy efficiency and renewable energy technologies. US National Renewable Energy Laboratory (NERL), pp. 47-54.

Srinivas N, Deb K (1994). Multiobjective optimization using nondominated sorting in genetic algorithms. Evol. Comput., 2: 221248.

Syswerda G, Palmucci J (1991). The application of genetic algorithms to resource scheduling. In Booker, Proc. 4th International Conf. GAs., pp. 502-508.

Tollefson G, Billinton R, Wacker G, Chan E, Aweya JA (1994). Canadian customer survey to assess power system reliability worth IEEE Trans. Power Syst., 9: 443-450.

Transformers' user mannual, Iran-Transfo Corporation (In persian).

US Energy Information Administration Glossary.

Wang C, Nehrir MH (2004). Analytical approaches for optimal placement of distributed generation sources in power systems. IEEE Trans. Power Syst., 19: 2068- 2076.

Willis HL (2004). Power Distribution Planning Reference Book, second edition, Marcel Dekker inc. pp. 331-381.

Willis HL, Scott WG (2000). Distributed Power Generation and Planning and Evaluation. Marcel DekKer, Chpt. 5.

Zhu D, Broadwater RP, Tam K, Seguin R, Asgeirsson H (2006). Impact of $D G$ placement on reliability and efficiency with time-varying loads. IEEE Trans. Power Syst., 21: 419-427.

Zitzler E, Thiele L (1999). Multiobjective evolutionary algorithms: a comparative case study and the strength Pareto approach. IEEE Trans. Evol. Comput., 3: 257-271. 
Appendix. List of the symbols.

\begin{tabular}{|c|c|c|c|}
\hline Symbol & Description & Symbol & Description \\
\hline $\mathrm{Net}_{-} \mathrm{COE}$ & Net cost of energy $(\$ / K W H)$ & $T_{I N}$ & Total Number of Interruption yearly \\
\hline$N_{D G}$ & Total number of distributed generation & $U_{i}$ & $I^{\text {th }}$ Interruption duration \\
\hline$P_{D G}$ & Distributed generation nominal power (KW) & $R$ & Branch resistance \\
\hline$D_{D G}$ & Distributed Generation working duration (days/yr) & $I$ & Branch current \\
\hline$I C C$ & Initial capital cost $(\$)$ & $M$ & Branch number \\
\hline$L C C$ & Land lease cost $(\$)$ & $V$ & Node voltage (pu) \\
\hline Initial_MOE & Initial miscellaneous operating expense (\$) & $N$ & Buses set \\
\hline$C R F$ & Capital recovery factor & $P_{\text {Load }}$ & Maximum load of the network (KW) \\
\hline$O \& M$ & Operation and maintenance cost $(\$ / y r)$ & $L$ & Branches set \\
\hline fuel_cost & Fuel cost $\left(\$ / \mathrm{m}^{3}\right)$ & $S_{S T}^{r}$ & Substation transformer rated capacity (KVA) \\
\hline Fuel_cost & Estimated fuel cost of $D G(\$ / y r)$ & $S_{C T}^{r}$ & Customer transformer rated capacity (KVA) \\
\hline Annual_MOE & Annual miscellaneous operating expense & $S_{C T}$ & Customer transformer loading (KVA) \\
\hline$I R$ & Interest rate & $P_{1}$ & Transformer Nameplate capacity rating(KVA) \\
\hline Life & Economic lifetime of DG (yrs) & $T$ & Environment temperature $\left({ }^{\circ} \mathrm{C}\right)$ \\
\hline$C C D F$ & Composite customer damage function & $H$ & Height of location above sea level $(\mathrm{m})$ \\
\hline$W_{S}$ & Weight of each sector is the system & $P_{k}$ & Short-Circuit power loss from the nameplate (KW) \\
\hline$T_{S}$ & Total number of sectors & $P_{0}$ & No-Load power loss from the nameplate (KW) \\
\hline$S C D F$ & Sector customer damage function & $P_{2}$ & Actual capacity of transformer (KVA) \\
\hline$J_{1}$ & $D G$ annual cost $(\$)$ & $V_{\min }, V_{\max }$ & Voltage standard limits allowed by regulation \\
\hline$J_{2}$ & Interruption cost $(\$)$ & $S_{S T}$ & $\begin{array}{l}\text { Actual delivered power by substation transformer } \\
\text { (KVA) }\end{array}$ \\
\hline$J_{3}$ & System power loss (KW) & & \\
\hline
\end{tabular}

